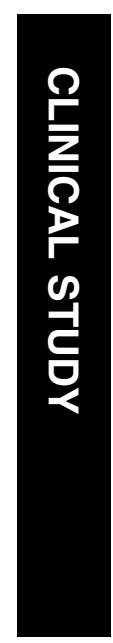

\title{
Intravitreal VEGF levels in uveitis patients and treatment of uveitic macular oedema with intravitreal bevacizumab
}

${ }^{1}$ Department of Ophthalmology, Medical University of Graz, Austria

${ }^{2}$ Department of Ophthalmology, General Hospital Klagenfurt, Austria

Correspondence:

Y El-Shabrawi,

Department of

Ophthalmology,

General Hospital Klagenfurt, St Veiterstraße 43,

A - 9020

Klagenfurt,

Austria

Tel: + 43463538 24203;

Fax: + 4346353823194 .

E-mail: yosuf.elshabrawi@

meduni-graz.at

Received: 3 April 2008 Accepted in revised form: 25 November 2008

Published online: 23 January 2009

Proprietary interest: None

\begin{abstract}
Purpose Clinical data suggest a role for VEGF in uveitic cystoid macular oedema (CME), even though the data on intravitreal VEGF levels in these eyes is still inconclusive. We determined intravitreal VEGF levels and treated uveitis patients with intravitreal bevacizumab. Methods Intravitreal VEGF levels were measured in eight uveitis patients and 10 controls using cytometric bead array technology. In 11 eyes of a second group of uveitis patients, CME was treated using $1.25 \mathrm{mg}$ bevacizumab intravitreally. Re-injections of bevacizumab were given in patients showing a transient positive effect, defined as an increase of the best-corrected vision of at least two lines on a snellen chart. Alternatively, triamcinolone was given in patients, not responding to bevacizumab. Results Mean intravitreal VEGF concentration was $82.75 \pm 171.71 \mathrm{pg} / \mathrm{ml}( \pm \mathrm{SD})$ (range, $0.0-502.1 \mathrm{pg} / \mathrm{ml}$ ), and below the detection levels in controls. A significant reduction of retinal thickness was seen at weeks $2(P=0.001)$ and $4(P=0.007)$. A significant improvement in VA was seen at week $2(P=0.02)$. Patients presenting with a CME in baseline fluorescein-angiogram responded well towards bevacizumab treatment, unless an extensive leakage from the choroid or a leakage of the optic disk was detectable. In these patients, only intravitreally administered triamcinolone led to a reduction of the CME. Conclusions Our data suggest that patients presenting with a diffuse leakage from the choroid in the fluorescein angiogram or an extensive leakage of the optic disk should be
\end{abstract}

K Weiss ${ }^{1,2}$, I Steinbrugger ${ }^{1}$, M Weger', N Ardjomand', R Maier', BJ Wegscheider', A Wedrich ${ }^{1}$ and $Y$ El-Shabrawi ${ }^{1,2}$ treated with intravitreal triamcinolone, whereas in patients presenting only a cystoid macular oedema bevacizumab treatment seems like a good choice.

Eye (2009) 23, 1812-1818; doi:10.1038/eye.2008.388; published online 23 January 2009

Keywords: bevacizumab; avastin; intreavitreal VEGF; cystoid macular oedema; treatment

Introduction

Cystoid macular oedema (CME) is a frequent complication in patients with intraocular inflammatory diseases, leading to a significant visual loss. ${ }^{1,2}$ Treatments include oral or periocular corticosteroids, sometimes given in combination with oral carbonic anhydrase inhibitors, ${ }^{3}$ immune-modulating drugs, such as anti-TNF- $\alpha$ therapy ${ }^{4-6}$ and intravitreally administered triamcinolone (TA). ${ }^{7,8}$

Macular oedema in the setting of uveitis, as also for diseases, such as diabetic retinopathy or retinal vein occlusions (RVOs), arises due to a disruption of the blood-retinal barrier, with consecutive exudation and accumulation of serous fluid. ${ }^{9}$ Evidence exists that VEGF is not only involved in the pathogenesis of CME in diabetes, RVO, but also in intraocular inflammatory diseases. Firstly, VEGF is 50000 times more potent than histamine in inducing vascular permability, ${ }^{10}$ and secondly, in experimental autoimmune uveitis (EAU), the expression of VEGF is markedly increased in the retina. ${ }^{11}$ In human uveitic eyes, the role of VEGF is, however, not yet clearly defined. Fine et $a l^{12}$ found increased VEGF concentrations in the aqueous humour of uveitis patients who 
presented with CME, when compared with those without macular oedema. A follow-up study by Banerjee et al ${ }^{13}$ was, however, unable to detect VEGF in the vitreous of uveitic eyes.

Clinical data, such as resolution rates of the uveitic macular oedema following anti-VEGF treatment, vary between the previously published studies. ${ }^{14-16}$ All studies used bevacizumab, a humanized monoclonal antibody that targets VEGF. Cordero Coma et $a l^{15}$ who treated 13 eyes of 13 patients found an improvement of vision in $62 \%$ of his patients after a single dose of bevacizumab. A second study carried out by Ziemssen et $a l^{14}$ observed only a transient and very limited effect in three out of six patients after bevacizumab treatment, and the most recent study by Mackensen et $\mathrm{l}^{16}$ described a positive effect of treatment in $72 \%$ of 10 patients. The differences in the treatment response seen could neither be addressed to the dosage used, 2.5 vs $1.25 \mathrm{mg}$, nor the time between the occurrence of the macular oedema and intravitreal bevacizumab treatment. To rationally decide the amounts of anti-VGF treatment needed in uveitic CME, it is necessary to know the intraocular levels achieved in uveitic eyes. So far, as only conflicting data on intraocular VEGF in uveitis patients exist, ${ }^{12,13}$ we first measured intravitreal VEGF in vitreous samples of eight uveitis patients. A second aspect of the study was to include fluorescein angiogram (FA) as a possible tool in distinguishing patients responding $v s$ patients lacking a response towards bevacizumab treatment. Finally, we compared the effect of bevacizumab to that of TA in uveitic CME non-responding towards bevacizumab after the first injection.

\section{Materials and methods}

\section{Evaluation of intravitreous VEGF levels}

To determine vitreous VEGF concentration among uveitis patients, we measured VEGF levels using cytometric bead array technology (CBA) in eight uveitis patients and 10 control subjects. (Table 1) Control subjects were treated for the presence of an epiretinal membrane or a macular hole. Four of the uveitis patients were vitrectomized for the presence of an intensive vitreous infiltration obscuring the visibility of the posterior pole. The remaining four patients showed a vitreomacular traction syndrome (VTMS) associated with an epiretinal membrane.

Undiluted vitreous samples were obtained during a standard three-port pars plana vitrectomy at the beginning of the surgery. The obtained specimen was immediately transferred into a sterile plastic tube on ice. Subsequently, the sample was centrifuged at 5000 r.p.m. for $10 \mathrm{~min}$, aliquoted and stored at $-70^{\circ} \mathrm{C}$ until assayed.

The concentration of VEGF was determined in the vitreous samples using the BDTM CBA Flex Set System, BDTM Human Soluble Protein Master Puffer Kit (Cat. no. 558246, BD Bioscience-Pharmingen, San Diego, CA, USA) and the BD ${ }^{\mathrm{TM}}$ CBA Flex Set for VEGF measurement (Cat. no. 558336, BD BiosciencePharmingen). Measurements were performed according to the manufacturers protocol and as described previously. ${ }^{17}$ In brief, The $\mathrm{BD}^{\mathrm{TM}} \mathrm{CBA}$ Flex Set contains a bead population with distinct fluorescence intensity as well as the appropriate phycoerythrin (PE) detection reagent and standard. The bead population is coated with capture antibodies specific to VEGF. As previously described, ${ }^{17}$ the bead population was incubated with recombinant standards or test samples to form sandwich complexes. After the addition of PE-conjugated detection antibodies, the samples were incubated again and then resolved in the FL-3 channel of an FACSCalibur flow cytometer (BD Bisocience-Pharmingen). The results were generated in graphic and tabular format by using the CBA analysis software (BD Bioscience-Pharmingen).

Table 1 Patient data, uveitis entities, current therapy, and concentrations of vascular endothelial growth factor (VEGF) in vitreous of group 1

\begin{tabular}{|c|c|c|c|c|c|}
\hline Patient & Age & Gender & Diagnosis & Current treatment & $\begin{array}{l}V E G F \text { in } p g / \\
m l \text { in vitreous }\end{array}$ \\
\hline 1 & 46 & $\mathrm{~F}$ & Herpes retinitis & Oral corticosteroids $25 \mathrm{mg}$ /day for 1 week, acyclovir & 34.08 \\
\hline 2 & 69 & $\mathrm{~F}$ & $\begin{array}{l}\text { Gliose, CME, disseminated } \\
\text { Chorioretinitis }\end{array}$ & Oral corticosteroids $5 \mathrm{mg} /$ day for $>6$ months & 3.88 \\
\hline 3 & 39 & M & Chronic iritis, no CME & Local corticosteroids & 0.00 \\
\hline 4 & 11 & M & Uveitis intermedia, CME & Local, corticosteroids & 502.10 \\
\hline 5 & 79 & $\mathrm{~F}$ & $\begin{array}{l}\text { Uveitis intermedia, epiretinal } \\
\text { membrane, CME }\end{array}$ & Oral corticosteroids $5 \mathrm{mg}$ /day for 28 months & 33.35 \\
\hline 6 & 41 & $\mathrm{~F}$ & chronic uveitis antibody, CME & Oral corticosteroids $7.5 \mathrm{mg}$ for 24 months & 6.49 \\
\hline 7 & 72 & M & Chronic iritis, no CME & Acyclovir, local corticosteroids & 0.00 \\
\hline 8 & 7 & M & JIA-associated uveitis, CME, & MMF $2 \mathrm{~g}$ /day, MTX $10 \mathrm{mg}$ /week, oral corticosteroids & 82.11 \\
\hline
\end{tabular}




\section{Intravitreal anti-VEGF treatment}

A second group comprised of 11 eyes of nine uveitis patients (Table 2; five women and four men) with continued loss of vision associated with cystoid macular oedema were treated with intravitreal injections of $1.25 \mathrm{mg}$ bevacizumab. Three of the patients were treated with systemic immune modulatory medication for a minimum of 6 months before intravitreal bevacizumab treatment. Infliximab was given at a dose of $5 \mathrm{mg} / \mathrm{kg} /$ body weight every 6 weeks to patients 2 and 3 , azathioprine was given at a dose of $2 \mathrm{mg} / \mathrm{kg} / \mathrm{body}$ weight per day to patient 2 , and mycophenolate moeftil was given at dose of $2 \mathrm{~g}$ per day to patient 3 .

Methotrexate was given at a dose of $20 \mathrm{mg}$ once weekly to patient 7 and $15 \mathrm{mg}$ once weekly to patient 9 .

No patient from the vitrectomy group, described above, has been included into the bevacizumab treatment group, as performing a vitrectomy alone has already been reported to have a positive influence on the inflammatory macular oedema. ${ }^{18}$

All patients were informed of potential benefits and side effects. The experimental nature of analyses was approved by the local ethics commission. Informed consent was given by all subjects. CME was verified by fundus examination, FA, and OCT scanning. FA was performed at baseline and 4 weeks after bevacizumab treatment. Visual acuity testing and measurements of central retinal thickness, using OCT were performed at baseline, weeks 1, 2, and 4. After a minimum of 4 weeks, retreatment with $1.25 \mathrm{mg}$ of bevacizumab was performed in eyes showing a transient positive response after the first bevacizumab injection, which was defined as an increase of at least two lines on the snellen chart. Patients lacking a positive response after intravitreal bevacizumab treatment defined as mentioned above were treated with $4 \mathrm{mg}$ of intravitreal TA.

Statistical analyses were performed using a two-tailed, paired $t$-test, as described previously. ${ }^{16}$ A $P$-value of $<0.05$ was considered statistically significant. For statistical evaluation, the visual acuity was converted from snellen into LogMar as described previously. ${ }^{16}$

\section{Results}

\section{Results on intraocular VEGF levels}

To obtain a rationale for the amounts of bevacizumab to be injected, we first measured intravitreal VEGF levels in eight uveitis patients and 10 control subjects. Patient data and uveitis entities, current therapy, and VEGF levels are presented in Table 1. The mean concentration of VEGF measured in our uveitis patients was $82.75 \mathrm{pg} / \mathrm{ml}$ \pm 171.71 ( \pm SD) (range, $0-502.1 \mathrm{pg} / \mathrm{ml}$ ). In the control group, VEGF was below the detection levels in all subjects. For comparison, in samples of our patients with diabetes, the mean intravitreal VEGF concentration was $954.98 \mathrm{pg} / \mathrm{ml}$ (range, $10-1325 \mathrm{pg} / \mathrm{ml}$; Maier et $\mathrm{al}^{19}$ ).

Table 2 Patient data, uveitis entities, and concurrent treatment from the second group treated with intravitreal bevacizumab and/or triamcinolone

\begin{tabular}{|c|c|c|c|c|c|c|}
\hline Eye no. & Age & Gender & Diagnosis & Therapy at the time of treatment & Macular oedema & $\begin{array}{l}\text { Duration of } \\
\text { the CME }\end{array}$ \\
\hline 1 & 46 & F & HLA B27 + AAU & $\begin{array}{l}\text { Local corticosteroids q4d for } 8 \\
\text { months }\end{array}$ & CME & 3 months \\
\hline 2 & 53 & F & Birdshot chorioretinitis & $\begin{array}{l}\text { Infliximab } 5 \mathrm{mg} / \mathrm{kg} / \mathrm{BWQ} \\
6 \text { weeks for }>1 \mathrm{a}, 100 \mathrm{mg} / \text { day } \\
\mathrm{AZT} \text {, oral corticosteroids } \\
5 \mathrm{mg} / \text { day }\end{array}$ & $\begin{array}{l}\text { Diffuse leakage from the } \\
\text { choroid and the optic disks }\end{array}$ & 20 months \\
\hline 3 & 45 & F & Retinal vasculitis & $\begin{array}{l}\text { Infliximab } 5 \mathrm{mg} / \mathrm{kg} / \mathrm{BWQ} \\
6 \text { weeks for }>1 \mathrm{a} \text {, } \\
\text { mycophenolate moeftil } 2 \mathrm{~g} / \text { day }\end{array}$ & $\begin{array}{l}\text { Diffuse leakage from the } \\
\text { choroid and the optic disks }\end{array}$ & 12 months \\
\hline 4 & 48 & F & Subacute anterior uveitis & $\begin{array}{l}\text { TA parabulbar injection } \\
\text { (1) } 3 \text { months before baseline }\end{array}$ & $\begin{array}{l}\text { Diffuse leakage from the } \\
\text { choroid and the optic disks }\end{array}$ & 4 months \\
\hline $5 \mathrm{a}$ & 58 & M & HLA B27-AAU & No treatment for $>3$ months & CME & 2 months \\
\hline $5 b$ & 58 & M & HLA B27-AAU & No treatment for $>3$ months & CME & 1 month \\
\hline $6 a$ & 40 & M & Intermediate uveitis & No treatment for $>3$ months & $\mathrm{CME}$, leakage of the optic disk & 7 months \\
\hline $6 b$ & 40 & M & Intermediate uveitis & No treatment for $>3$ months & $\mathrm{CME}$, leakage of the optic disk & 7 months \\
\hline 7 & 48 & M & HLA B27 + AAU & $20 \mathrm{mg} /$ week MTX for 2 months & CME & 2 months \\
\hline 8 & 31 & M & HLA B27 + AAU & $\begin{array}{l}\text { Local corticosteroids q2d for } \\
2 \text { months }\end{array}$ & $\mathrm{CME}$ & 2 months \\
\hline 9 & 49 & F & HLA B27- AAU & $\begin{array}{l}15 \mathrm{mg} / \mathrm{kg} / \text { week MTX } \\
>12 \text { months }\end{array}$ & $\mathrm{CME}$ & 1 month \\
\hline
\end{tabular}

$\mathrm{AAU}=$ acute anterior uveitis; bev $=$ bevacizumab; $\mathrm{CME}=$ cystoid macular oedema; $\mathrm{F}=$ female; HLA =human leukocyte antigen; $\mathrm{M}=$ male; $\mathrm{TA}=$ triamcinolone; $\mathrm{MTX}=$ methotrexate; $\mathrm{AZT}=$ azathioprine.

$5 a$ is the right eye, $5 b$ is the left eye of one patient. $6 a$ is the right eye, and $6 b$ is the left eye of one patient. 
Data published on intravitreal VEGF levels among patients with exsudative age-related macular degeneration (AMD) were below $64 \mathrm{pg} / \mathrm{ml}$.

Owing to the fact that the intravitreal VEGF levels we found in our uveitis patients were comparable with those seen in case of AMD patients, we decided to use $1.25 \mathrm{mg}$ bevacizumab, the amount usually used in patients with exsudative AMD.

\section{Results of intravitreal anti-VEGF treatment}

The second group comprised of 11 eyes of 9 patients were treated with $1.25 \mathrm{mg}$ bevacizumab. Patient data, uveitis entities, and concurrent treatment are shown in Table 2. The mean age was $46.4 \mathrm{SD} \pm 7.7$ years (range, $31-58$ ). Data on visual acuity is presented in Table 3 . Central retinal thickness as measured by OCT is shown in Table 4 . The presence of fluorescein leakage of the optic disk was seen at a very low level in six out of eleven eyes (Figure 1), where as an extensive leakage of the macula was found in four eyes (patients 2, 3, 4, and 6a (6a is the right eye); Figure 2). An extensive diffuse leakage from the choroid, as shown in Figure 3, suggesting an extensive alteration of the outer blood-retinal barrier was seen in three eyes (patients 2, 3, and 4). The visual acuity changes after 2 weeks were statistically significant

Table 3 Visual acuity (VA) in LogMar from patients treated with bevacizumab, and retreatment with bevacizumab and triamcinolone (TA)

\begin{tabular}{|c|c|c|c|c|c|c|c|c|c|}
\hline Eye no. & $\begin{array}{l}\text { VA before } \\
\text { treatment }\end{array}$ & $\begin{array}{l}\text { VA after } \\
1 \text { week }\end{array}$ & $\begin{array}{l}\text { VA after } \\
2 \text { weeks }\end{array}$ & $\begin{array}{l}\text { VA after } \\
4 \text { weeks }\end{array}$ & $\begin{array}{l}\text { Number of } \\
\text { bevacizumab } \\
\text { injection }\end{array}$ & $\begin{array}{c}\text { Number of TA } \\
\text { injection }\end{array}$ & $\begin{array}{l}\text { VA before } \\
\text { re-treatment }\end{array}$ & $\begin{array}{c}\text { Best vision after } \\
\text { re-treatment }\end{array}$ & $\begin{array}{c}\text { Best result } \\
\text { after re-treatment }\end{array}$ \\
\hline 1 & 0.6 & 0.4 & 0.2 & 0.5 & 2 & & 0.5 & 0.2 & 3 \\
\hline 2 & 1.0 & 1.0 & 1.0 & 1.0 & 1 & & & & \\
\hline 3 & 0.3 & 0.3 & 0.5 & 0.5 & 1 & 1 & 0.7 & $0.1^{\mathrm{b}}$ & 6 \\
\hline 4 & 0.4 & 0.2 & 0.5 & 0.7 & 1 & 1 & 0.7 & 0.3 & 4 \\
\hline $5 a$ & 0.4 & 0.2 & 0.2 & 0.1 & 2 & & 0.6 & 0.2 & 5 \\
\hline $5 b$ & 0.3 & 0.1 & 0.0 & 0.0 & 2 & & 0.7 & 0.0 & 7 \\
\hline $6 a$ & 0.2 & 0.2 & 0.1 & 0.6 & 1 & & & & \\
\hline $6 b$ & 0.4 & 0.1 & 0.1 & 0.2 & 1 & & & & \\
\hline 7 & 0.6 & 0.5 & 0.3 & 0.5 & 2 & & 0.5 & 0.3 & 4 \\
\hline 8 & 0.2 & 0.1 & 0.1 & 0.0 & 2 & & 0.1 & 0.0 & 1 \\
\hline 9 & 0.2 & 0.0 & 0.0 & 0.0 & 2 & & 0.0 & 0.0 & 1 \\
\hline Mean & 0.42 & 0.28 & 0.27 & 0.37 & & & 0.59 & 0.23 & \\
\hline
\end{tabular}

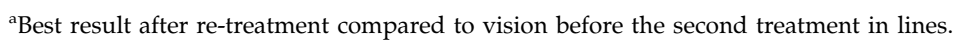

${ }^{b}$ Cataract surgery has been performed due to the lack of an adequate visibility of the fundus.

Table 4 Central retinal thickness in $\mu \mathrm{m}$

\begin{tabular}{|c|c|c|c|c|c|c|c|c|}
\hline Eye no. & $\begin{array}{c}\text { Retinal thickness } \\
\text { before } \\
\text { treatment }\end{array}$ & $\begin{array}{c}\text { Retinal } \\
\text { thickness } \\
\text { after } 1 \text { week }\end{array}$ & $\begin{array}{l}\text { Retinal thickness } \\
\text { after } 2 \text { weeks }\end{array}$ & $\begin{array}{l}\text { Retinal thickness } \\
\text { after } 4 \text { weeks }\end{array}$ & $\begin{array}{l}\text { Number of } \\
\text { AV injection }\end{array}$ & $\begin{array}{l}\text { Number of } \\
\text { TA injection }\end{array}$ & $\begin{array}{c}\text { Retinal thickness } \\
\text { before } \\
\text { re-treatment }\end{array}$ & $\begin{array}{c}\text { Retinal thickness } \\
4 \text { weeks after } \\
\text { re-treatment }\end{array}$ \\
\hline 1 & 739 & 490 & 500 & 500 & 2 & & 589 & 507 \\
\hline 2 & 622 & 481 & 639 & 597 & 1 & & & \\
\hline 3 & 598 & 415 & 450 & 500 & 1 & 1 & 437 & 290 \\
\hline 4 & 614 & a & 523 & 647 & 1 & 1 & 647 & 340 \\
\hline $5 b$ & 531 & 348 & 340 & 357 & 2 & & 598 & 340 \\
\hline $6 a$ & 630 & 439 & 514 & 681 & 1 & & & \\
\hline $6 b$ & 689 & 572 & 675 & 599 & 1 & & & \\
\hline 7 & 647 & 415 & 481 & 497 & 2 & & 497 & 515 \\
\hline 8 & 464 & 464 & 431 & 423 & 2 & & 423 & 381 \\
\hline 9 & 497 & 315 & 323 & 298 & 2 & & 298 & 298 \\
\hline Mean & 586.7 & 437.7 & 487.6 & 493.7 & & & 568.1 & 389.8 \\
\hline
\end{tabular}

$\mathrm{TA}=$ triamcinolone

A reduction of the retinal thickness was seen in all eyes after the first or second week.

${ }^{\mathrm{a} O C T}$ not performed. 


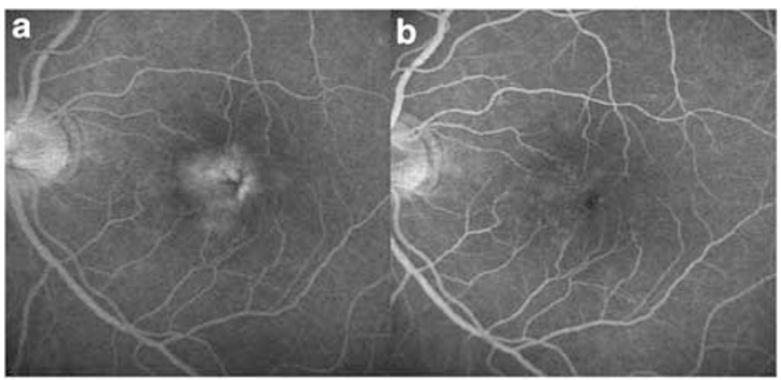

Figure 1 Late phase of the fluorescein angiogram at base line and 4 weeks after treatment with $1.25 \mathrm{mg}$ bevacizumab: Eyes presenting only with a cystoid macular oedema (a) responded well (b) towards intravitreal bevacizumab treatment; for example, the eye $6 b$ (the left eye of the patient) showing an increase in visual acuity by three lines and a reduction of retinal thickness seen using OCT at week 4 after the bevacizumab injection.

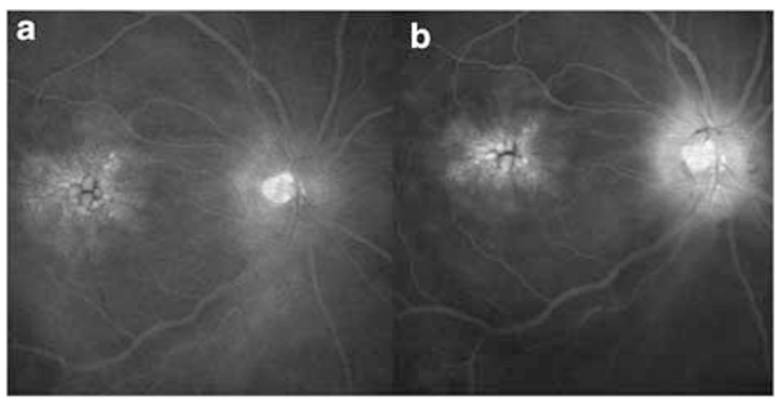

Figure 2 There was no effect of intravitreal bevacizumab treatment at week 4 in eyes with an extensive leakage of choroid and the optic disk (a) seen in the fluorescein angiogram (b); for example, patient 4 presented with a diffuse leakage from the choroid accompanied by an extensive fluorescein leakage of the optic disk. The patient lost one line in VA after 2 weeks despite bevacizumab therapy. Treatment with triamcinolone, on the other hand, could raise the VA from 20/100 to 20/40.



Figure 3 Diffuse leakage due the changes in the outer retinalblood barrier (a) showed no change in fluorescein angiogram 4 weeks after bevacizumab (b). OCT showed a reduction of retinal thickness, but patient 3 had a loss of two lines in VA. Treatment with triamcinolone had a positive effect, the VA raised from $20 / 100$ to $20 / 25$ (intermediate cataract surgery) and led to a reduction of retinal thickness from 437 to $290 \mu \mathrm{m}$ after 4 weeks.
$(P=0.02)$. An improvement of visual acuity was seen in nine out of eleven eyes at week 1 or 2 . Compared to week 1 or two, seven of these nine eyes lost at least one line within the following 2 weeks.

Thus, at week 4 , even though seven eyes still showed an improvement in vision when compared to baseline, only three eyes remained at their best visual acuity achieved after bevacizumab treatment, suggesting that the effect of intravitreal bevacizumab is only transient in most patients treated, as already described. ${ }^{14-16}$

A reduction of retinal thickness was seen in all eyes in week 1 or 2 . The mean retinal thickness, as measured by OCT, was $586.7 \pm 97 \mu \mathrm{m}$ before bevacizumab treatment. After 1 week, the mean retinal thickness was $437.7 \pm 77 \mu \mathrm{m}$, and it was $487.7 \pm 112$ and $493.7 \pm 129 \mu \mathrm{m}$ at weeks 2 and 4 , respectively. The reduction of retinal thickness was statistically significant comparing baseline to weeks $2(P=0.001)$ and $4(P=0.007)$. Retreatment with bevacizumab was performed in six eyes, at week 4 after the first injection. Data are presented in Tables 3 and 4. One patient (patient 6) refused any additional intravitreal treatment, using either bevacizumab or TA, which was given alternatively in patients lacking an effect of bevacizumab treatment. In these patients, intravitreal TA was very effective in reducing the CME (Tables 3,4). OCT pictures are shown in Figure 4. One patient (patient 2) received one intravitreal injection of TA into the contralateral eye that has been treated with bevacizumab. The TA-treated eye showed an improvement of visual acuity from $20 / 800$ to $20 / 200$, the bevacizumab-treated eye remained at a visual acuity of 20/200. Intravitreal TA resulted in intraocular pressure raise above $35 \mathrm{mmHg}$; thus, the patient has not been retreated with TA despite the lack of an effect of intravitreal bevacizumab (data shown in Tables 3,4). Retreating patients showing a transient improvement in their visual acuity with one bevacizumab injection lead to similar improvement of their visual acuity after the second injection. The retinal thickness reduction seen in OCT improved from a mean of $568.1 \pm 122.35 \mu \mathrm{m}$ to a mean of $389.8 \pm 88.93 \mu \mathrm{m}(P=0.03)$. Indicating that the retreatment is at least as successful as the first injection in eyes showing a positive response after the first injection.

\section{Conclusions}

We have treated 11 eyes in nine uveitis patients for their CME with $1.25 \mathrm{mg}$ intravitreal bevacizumab. The dose of $1.25 \mathrm{mg}$ was used, as intraocular VEGF levels that we detected in the vitreous of uveitis patients were similar to those described in patients with adult macular degeneration, where $1.25 \mathrm{mg}$ is the most commonly used dosage. ${ }^{20}$ 
We found a positive response to intraocular bevacizumab treatment only in eyes with limited macular and/or optic disk leakage in the FA (Figure 1),

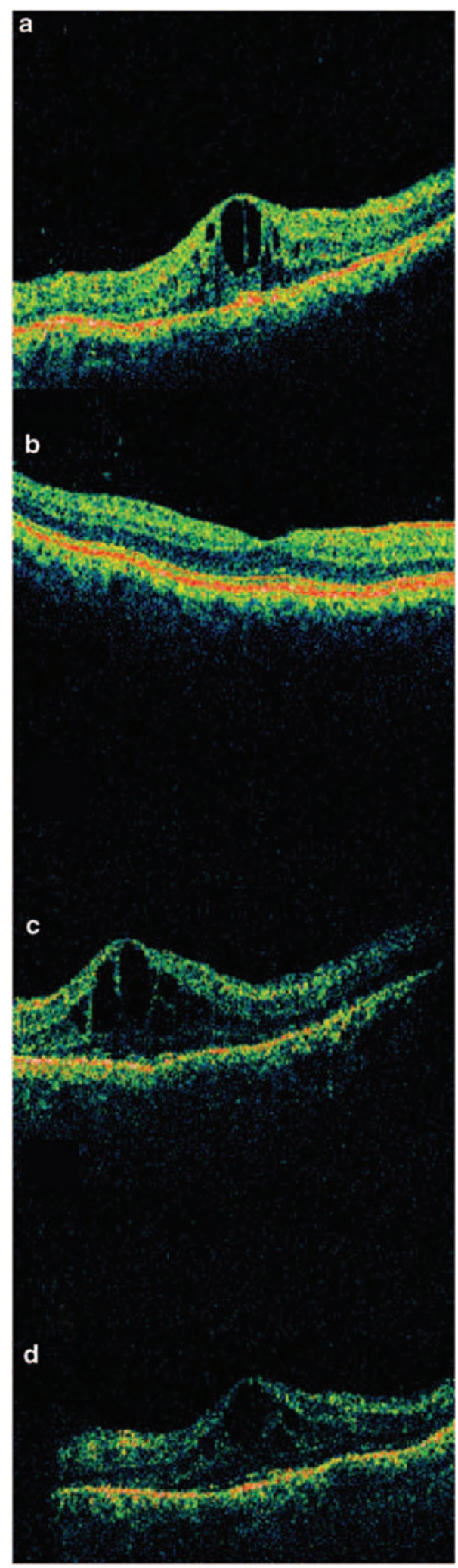

recapitulating the positive response of the patient, whose FA is presented by Cordero Coma et al. ${ }^{15}$ Eyes showing an extensive fluorescein leakage from the choroid and the optic disks (Figures 2 and 3) did not respond with an increase in visual acuity following bevacizumab treatment. In these eyes, only intravitreal TA was able to induce an increase in vision, suggesting that in eyes with diffuse fluorescein leakage from the choroid TA rather than bevacizumab might be the treatment of choice. A possible explanation for the superiority of TA over bevacizumab in these eyes might be, that depending on the type of pathological condition causing the oedema and the stage of the uveitis, the relative contributions of different vascular permeabilityenhancing mediators may vary and other factors, such as cytokines $^{21}$ or metalloproteinases, ${ }^{22}$ may play a more prominent role. An alternative treatment option to intravitreal TA might be the use of a combined treatment modality by (a) blocking the effect of intraocular VEGF released in case of an intraocular inflammation using bevacizumab and (b) a modification of the systemic treatment, using for instance of biologics, such TNF- $\alpha$ blocking antibodies, to maintain the uveitis under control and block, if possible, the effects of cytokines and/or metalloproteinases.

The positive effect of both intravitreal bevacizumab as well as TA was only transient. Even though nine eyes showed a gain in vision of at least two lines on the snellen chart in the first 2 weeks, in only three eyes, this gain of vision was sustained over the follow-up period. The fact that eyes responding with an increase of at least two lines on the snellen chart after the first injection, responded to the retreatment with a comparable gain of vision, indicate that the effect of bevacizumab is repeatable.

In conclusion, we found a positive effect of bevacizumab treatment in uveitic macular oedema in eyes lacking an extensive breakdown of the outer bloodretinal barrier or an extensive leakage of optic disk as seen in the FA. In these patients, intravitreal TA seems to be the better treatment option. A major limitation of our study is the small number of patients included, thus larger studies are warranted.
Figure 4 Treatment with triamcinolone compared with bevacizumab in eyes with extensive diffuse leakage and/or leakage of the optic disk in FA. Patient 3 showed a good response towards treatment with triamcinolone. After 4 weeks, the retinal thickness was reduced from $647 \mu \mathrm{m}$ (a) to $340 \mu \mathrm{m}$ (b), and the VA raised from $20 / 100$ to $20 / 40$ becavizumab treatment in this patient had almost no effect and the patient lost two lines in VA. The retinal thickness before (c) and after 4 weeks of intravitreal becavizumab injection $(\mathrm{d})$. 


\section{References}

1 Arend O, Remky A, Harris A, Bertram B, Reim M, Wolf S. Macular microcirculation in cystoid maculopathy of diabetic patients. Br J Ophthalmol 1995; 79(7): 628-632.

2 Angunawela RI, Heatley CJ, Williamson TH, Spalton DJ, Graham EM, Antcliffe RJ et al. Intravitreal triamcinalone acetonide for refractory uveitic cystoid macular oedema: long-term management and outcome. Acta Ophthalmol Scand 2005; 83(5): 595-599.

3 Schilling H, Heiligenhaus A, Laube T, Bornfeld N, Jurklies B. Long-term effect of acetazolamide treatment of patients with uveitic chronic cystoid macular edema is limited by persisting inflammation. Retina 2005; 25(2): 182-188.

4 El-Shabrawi Y, Mangge H, Hermann J. Anti-tumour necrosis factor alpha treatment in chronic recurrent inflammation of the anterior segment of the eye in patients resistant to standard immunomodulatory treatment. Ann Rheum Dis 2003; 62(12): 1243-1244.

5 Markomichelakis NN, Theodossiadis PG, Pantelia E, Papaefthimiou S, Theodossiadis GP, Sfikakis PP. Infliximab for chronic cystoid macular edema associated with uveitis. Am J Ophthalmol 2004; 138(4): 648-650.

6 Murphy CC, Greiner K, Plskova J, Duncan L, Frost A, Isaacs JD et al. Neutralizing tumor necrosis factor activity leads to remission in patients with refractory noninfectious posterior uveitis. Arch Ophthalmol 2004; 122(6): 845-851.

7 Jonas JB, Kreissig I, Degenring R. Intravitreal triamcinolone acetonide for treatment of intraocular proliferative, exudative, and neovascular diseases. Prog Retin Eye Res 2005; 24(5): 587-611.

8 Kok H, Lau C, Maycock N, McCluskey P, Lightman S. Outcome of intravitreal triamcinolone in uveitis. Ophthalmology 2005; 112(11): 1916.e1-1916.e7.

9 Aiello LP. Vascular endothelial growth factor and the eye: biochemical mechanisms of action and implications for novel therapies. Ophthalmic Res 1997; 29(5): 354-362.

10 Senger DR, Connolly DT, Van de Water L, Feder J, Dvorak HF. Purification and NH2-terminal amino acid sequence of guinea pig tumor-secreted vascular permeability factor. Cancer Res 1990; 50(6): 1774-1778.

11 Vinores SA, Chan CC, Vinores MA, Matteson DM, Chen YS, Klein DA et al. Increased vascular endothelial growth factor (VEGF) and transforming growth factor beta (TGFbeta) in experimental autoimmune uveoretinitis: upregulation of
VEGF without neovascularization. J Neuroimmunol 1998; 89(1-2): 43-50.

12 Fine HF, Baffi J, Reed GF, Csaky KG, Nussenblatt RB. Aqueous humor and plasma vascular endothelial growth factor in uveitis-associated cystoid macular edema. Am J Ophthalmol 2001; 132(5): 794-796.

13 Banerjee S, Savant V, Scott RA, Curnow SJ, Wallace GR, Murray PI. Multiplex bead analysis of vitreous humor of patients with vitreoretinal disorders. Invest Ophthalmol Vis Sci 2007; 48(5): 2203-2207.

14 Ziemssen F, Deuter CM, Stuebiger N, Zierhut M. Weak transient response of chronic uveitic macular edema to intravitreal bevacizumab (Avastin). Graefes Arch Clin Exp Ophthalmol 2007; 245(6): 917-918.

15 Cordero Coma M, Sobrin L, Onal S, Christen W, Foster CS. Intravitreal bevacizumab for treatment of uveitic macular edema. Ophthalmology 2007; 114 (8): 1574.e1-1579.e1.

16 Mackensen FHC, Becker MD, Heiligenhaus A. Intravitreal bevacizumab (AVASTIN) as a treatment for refractory macular edema in patients with uveitis: a pilot study. Retina 2008; 28(1): 41.

17 Maier R, Weger M, Haller-Schober EM, El-Shabrawi Y, Theisl A, Barth A et al. Application of multiplex cytometric bead array technology for the measurement of angiogenic factors in the vitreous. Mol Vis 2006; 12: 1143-1147.

18 Rothova A. Inflammatory cystoid macular edema. Curr Opin Ophthalmol 2007; 18(6): 487-492.

19 Maier R, Weger M, Haller-Schober EM, El-Shabrawi Y, Wedrich A, Theisl A et al. Multiplex bead analysis of vitreous and serum concentrations of inflammatory and proangiogenic factors in diabetic patients. Mol Vis 2008; 14: 637-643.

20 Duh EJ, Yang HS, Haller JA, De Juan E, Humayun MS, Gehlbach P et al. Vitreous levels of pigment epitheliumderived factor and vascular endothelial growth factor: implications for ocular angiogenesis. Am J Ophthalmol 2004; 137(4): 668-674.

21 Wakefield D, Lloyd A. The role of cytokines in the pathogenesis of inflammatory eye disease. Cytokine 1992; 4(1): 1-5.

22 El-Shabrawi YG, Christen WG, Foster SC. Correlation of metalloproteinase-2 and -9 with proinflammatory cytokines interleukin-1b, interleukin-12 and the interleukin-1 receptor antagonist in patients with chronic uveitis. Curr Eye Res 2000; 20(3): 211-214. 